\title{
材料化学课程线上教学初探
}

\author{
李媛媛 $1,{ }^{*}$, 何娟 ${ }^{1}$, 李恺 $2,{ }^{*}$ \\ 1 河南工业大学化学化工学院, 郑州 450001 \\ 2 郑州大学化学学院, 郑州 450001
}

\begin{abstract}
摘要: 2020 新年伊始, 新冠肺炎突然来袭, 为了防止聚集性感染, 教育部提出了 “停课不停教、停课不停学” 的要 求。地方普通高校学生的自律性、自觉性及能动性差别十分明显, 这样的学情对如何有效开展化学专业的线上教学 工作提出了更大的挑战。本文以材料化学课程线上教学为例, 介绍地方普通高校化学专业线上教学工作的开展情况。 针对教学过程中遇到的各种问题和采用的应对方案, 探讨线上教学过程中的注意事项。希望本文能为地方普通高校 化学专业线上教学工作提供有益的参考。
\end{abstract}

关键词: 新冠肺炎; 线上教学; 地方普通高校; 化学专业

中图分类号: G64; O6

\section{A Preliminary Study on the Online Teaching of Materials Chemistry}

\author{
Yuanyuan $\mathrm{Li}^{1, *}$, Juan $\mathrm{He}{ }^{1}$, Kai Li ${ }^{2, *}$ \\ ${ }^{1}$ School of Chemistry and Chemical Engineering, Henan University of Technology, Zhengzhou 450001, P. R. China. \\ ${ }^{2}$ College of Chemistry, Zhengzhou University, Zhengzhou 450001, P. R. China.
}

\begin{abstract}
At the beginning of the New Year in 2020, Corona Virus Disease 2019 (COVID-19) suddenly swept across the country. In order to prevent the infection caused by crowd, "Suspended classes but not stop teaching and learning" was proposed by the Ministry of Education. Students in local colleges and universities show obvious variations in selfdiscipline, consciousness and initiative. Such a practical situation brings us a great challenge to effectively carry out the online teaching for chemistry major. Taking the online teaching of "Materials Chemistry" as an example, this paper introduces the process of online teaching of chemistry major in the local universities. In view of the problems encountered in the teaching process and the solutions adopted, this paper summarizes the issues needing attention during the online teaching. It is hoped that this paper can provide some useful reference for the online teaching of chemistry major in local colleges and universities.
\end{abstract}

Key Words: Corona Virus Disease 2019; Online teaching; Local colleges and universities; Chemistry major

在全国抗击新冠肺炎疫情的形势下, 教育部提出 “停课不停教、停课不停学” 的要求 ${ }^{[1]}$ 。如何能 够在新学期里快速实现这一目标, 成为了教师和学生需要共同面对的新课题。作为地方普通高校的 教师, 笔者在新学期承担本科生的材料化学、分析化学等课程的讲授任务。根据授课对象、课程性 质的不同, 需要采用不同的策略组织教学, 确保教学效果和质量。

与重点高校优秀的生源水平相比, 地方普通高校的学生在自律性、自觉性及能动性方面具有明 显差别。以河南工业大学化学化工学院为例, 同一年级中, 既有一本的学生又有二本的学生。这样

收稿: 2020-03-03; 录用: 2020-03-10; 网络发表: 2020-03-19

“通讯作者, Email: yuanyuanli@haut.edu.cn; likai@zzu.edu.cn

基金资助: 河南工业大学本科教育教学改革研究与实践项目 
的学情, 对如何有效开展线上教学工作提出了更大的挑战。在这样的背景下, 结合多年的线下教学 经验, 笔者在开课前进行了充分的准备, 在课堂中进行了多样的尝试和及时的调整, 取得了良好的 教学效果。本文以材料化学课程教学为例, 分享在课程准备、课堂教学实施过程中遇到的问题和改 进措施，希望能为地方普通高校化学专业线上教学工作提供有益的参考。

\section{1 教学准备工作}

\section{1 确定授课方式}

在开课前, 首先需要确定课堂授课方式。为了课程的顺利开展, 笔者选择多线并行的 “线上直 播授课 + 视频材料学习 + 课堂讨论与测验” 的方式进行授课, 以确保线上授课质量。采用 “一平三 端智慧教学系统” ——超星学习通(下文简称学习通)网络平台进行建课, QQ 群联络学生及发布课程 相关信息, 腾讯课堂直播平台进行线上授课。

\section{2 采用学习通建课}

建课时需要做好以下几方面工作: (1) PPT 内容制作。为了适应学生在家里线上学习的需要, 需 要调整 PPT 尺寸为 $16: 9$ 以更适合手机观看。(2) 准备适当的网络视频资源。针对线上教学特点, 充分利用网络资源, 可以把一些课程内容生动地呈现在学生面前, 并起到拓展课程内容的作用。在 这步中, 视频应难度适中、时长合适、有较高的清晰度。(3) 课堂测验和课后作业题整理。课堂测验 的主要目的是针对教师与学生无法面对面的情况, 督促自律性较差的学生时刻紧跟课堂进度, 同时, 也可以检验学生每次课的学习效果。作业题在每章内容之后发放, 检验学生每章知识点的学习效果。 (4) 将 PPT、视频、测验和作业题等材料上传至学习通, 使学生可提前看到相关章节中的 PPT 和视 频内容, 方便学生提前进行预习。(5) 将 PPT、视频材料设置任务点 ${ }^{[2]}$ 。设置任务点后, 平台会自动 记录和统计学生学习此任务点的详细数据, 对学生的学习起到重要的监督作用。

\section{3 建立线上班级 $Q Q$ 群}

学习通作为一个学习软件, 许多学生并没有经常登录的习惯。如何能让学生第一时间了解学习 通的更新状态以及教师发布的通知, 需要借助学生最常用的一些社交软件进行信息发布。QQ 和微 信是现代学生广泛使用的社交软件。采用 $\mathrm{QQ}$ 群或微信群建立线上班级群, 在群内发布上课预告、 通知信息等, 利用其@功能, 可保证大部分学生能第一时间看到相关信息, 具有极强的时效性。相 对于微信群传输文件大小受限的缺点, $\mathrm{QQ}$ 群可传送大容量文件, 并可较长时间内存放于群文件中, 具有独特的优势。针对材料化学课程的授课特点, 提前上传一部分视频材料在 QQ 群文件中作为备 用资源, 能一定程度上弥补学习通网络崩溃或其他意外情况造成的无法学习的问题。

\section{4 提前网上试课}

为了让学生对课程授课方式及所采用的软件有所了解, 提前进行网络试课十分重要。采用腾讯 课堂直播平台进行共享电脑桌面/PPT/视频/摄像头等方面的调试, 练习在课堂上打卡、举手、连麦上 镜互动或在讨论区互动等功能 ${ }^{[3]}$ 。同时, 让学生在学习通上签到, 学习视频材料, 完成测验题。经过 试课，教师与学生完成对这些软件的 “磨合”，以保证正式上课时对软件功能的良好使用。

\section{2 线上教学实施过程及遇到的问题和解决方案}

\section{1 线上教学实施过程}

以材料化学课程为例, 简述基于 “学习通 $+\mathrm{QQ}$ 群 + 腾讯课堂” 的教学实践过程。

(1) 上课前, 教师提前 $20 \mathrm{~min}$ 登录学习通、 $\mathrm{QQ}$ 及腾讯课堂, 在 $\mathrm{QQ}$ 群里@全体成员, 提醒学生 登录学习通, 并随时关注 QQ 群内信息。

(2) 上课前 $15 \mathrm{~min}$, 于学习通内生成签到二维码, 并复制至 QQ 群内, 通知所有学生采用学习 通扫码签到。

(3) 上课前 $10 \mathrm{~min}$, 于腾讯课堂内生成邀请学生上课的网址及二维码, 并复制至 $\mathrm{QQ}$ 群内, 通 
知所有学生进入腾讯课堂, 宣布课堂纪律。

(4) 正式上课时, 首先采用腾讯课堂直播讲解本节课 PPT 中的重点。为了能第一时间了解学生 所看到和听到的信息, 笔者特意使用另一账号登录腾讯课堂同步听课, 以便及时发现断线、视频播 放卡顿等问题。学生如有疑问, 可举手提问, 也可在留言区内提问, 教师实时解答, 保证了课堂的 教学效果。

(5) 直播授课过程中, 穿插学习学习通中所准备的视频材料。同时, 结合视频中的内容, 布置课 堂测验题。教师根据课程安排继续直播授课, 讲解测验题或安排学生进行课堂讨论。授课结束前, 布置课后作业及安排下节课的预习内容。

(6) 授课结束后, 在 $\mathrm{QQ}$ 群里总结本节课的考勤与课堂情况; 通过学习通查询学生任务点完成 情况, 评阅课后作业。

\section{2 线上教学实施案例}

\subsection{1 案例 1: “材料结构一一晶体缺陷” 课程章节}

根据教学大纲, 本章节主要对点缺陷、线缺陷、面缺陷、体缺陷等几种缺陷进行介绍。

在制作 PPT 时, 笔者特别选择了一些动画插入到 PPT 中, 比如位错是如何产生的、位错是如何滑 移或攀移的, 以便学生直观地了解相关知识。在直播授课时, 首先对四种缺陷进行简要介绍。在这期 间, 穿插安排学生学习已上传至学习通中的视频材料。这些视频材料在课前已进行了精挑细选, 包括 中南大学录制的《材料科学基础》慕课视频中的相关内容 ${ }^{[4]}$ 、《什么是位错》 ${ }^{[5]}$ 、《什么是螺位错》[ 6 等 三个视频。选择视频内容的原则首先是与本课程的教学内容高度吻合, 其次要具有清晰度高、重难 点突出的特点, 且时长较短, 适合课堂教学中的播放。为了督促学生认真观看视频, 在视频结束后, 发放 5 道测验题(设置为选择题、判断题等客观题型, 使教师在学习通中可及时看到练习效果), 答 题时间不超过 $5 \mathrm{~min}$ 。随后, 根据学生的完成情况, 对测验题进行讲解, 同时梳理视频中涉及的知识 点。课后作业的安排除了客观题型, 还加入论述题等主观题型, 以尽量避免互相抄袭的情况。课后 作业预计总完成时间 20-30 min, 涉及整节课的内容, 以便对学生的学习情况进行全面的考察。

在此案例中, 学生给出了视频内容较为单一、作业题题量较多且难度较大等反馈意见。针对这 些反馈, 在后续的课程中, 笔者及时进行了调整, 详见案例 2 。

\subsection{2 案例 2: “金属材料一一形状记忆合金” 课程章节}

根据教学大纲，本章节主要对形状记忆合金的组成、结构、性能与应用进行介绍。

在直播授课时, 首先简要介绍形状记忆合金的基础知识。然后, 选择一些介绍形状记忆合金的 视频材料提供给学生在学习通里学习。根据学生对之前课程的反馈意见, 本章节着重挑选了一些科 普性、趣味性强的视频, 如《超神奇! 形状记忆物质》 [7]、《神奇的记忆合金! 让假花在光照下尽情 绽放》 ${ }^{[8]}$ 等视频材料。由于部分视频资源时长较长, 在上传至学习通时, 笔者通过学习通的剪辑功能 对视频进行了剪辑, 使之更合适在教学过程中播放。直播授课和视频材料学习之后, 安排 $5 \mathrm{~min}$ 课 堂讨论: 根据形状记忆合金的相变原理, 你如何将其设计成发电机? 学生可以在 QQ 群内自由讨论, 也可以在腾讯课堂交流。约 $5 \mathrm{~min}$ 后, 随机邀请 1-2 位学生回答, 并根据回答情况进行点评。在这 期间, 学生围绕题目各抒己意, 起到了非常好的学习效果, 同时也活跃了课堂气氛。课后的作业题 为 “从中国知网、万方数据库等查阅一篇以形状记忆合金为关键词的文献, 并分析文献中材料的组 成、结构、性能与应用, 写成 300 字左右的总结” (注: 疫情期间, 河南工业大学向学生开放 VPN 服 务, 使其在家中即可登录图书馆的数据库)。通过这样的主观作业题, 既培养了学生查阅及阅读文献 的能力, 又拓展了知识面, 而且难度不至于太大, 也不会显得枯燥无味。

在此案例中, 学生对视频资源的反馈非常积极。由于视频资源的趣味性, 许多学生在课下要求 老师再多提供一些相关视频, 进行拓展学习。笔者通过 QQ 群, 分享了相关的视频资源或网址, 任 其自由选择。通过对本章节作业完成情况的分析可发现, 在本章作业中基本没有出现雷同情况, 说 明主观作业题的设置可有效防止学生间的作业抄袭。 


\section{3 遇到的问题和解决方案}

随着课程的进行, 各种各样的问题陆续出现, 尤其是部分学生居家学习纪律性差、自觉性差等 问题暴露显著。以下简述一些代表性问题及采取的解决方案。

(1) 迟到或旷课。上课初期, 部分学生不按时签到的现象比较突出, 甚至有部分学生自上课前的 预告至下课结束均联系不上。学生迟到或旷课最多的理由是忘记上课时间或起晚了。针对这些情况, 上课前 $20 \mathrm{~min}$ 即开始在 $\mathrm{QQ}$ 群里使用@功能提醒学生上课时间, 并且在签到时反复提醒, 对上课前 $5 \mathrm{~min}$ 尚未签到的学生落实到具体的班干部直接电话联系。确保不发生因为忘记时间而不上课的情 况。

(2) 学习通签到后但未参加上课。这部分学生往往是上述提及的有过迟到或旷课经历的学生, 对待学习态度不够认真。针对此现象, 采用 “学习通 + 腾讯课堂” 双签制度, 课前采用学习通签到, 上课时腾讯课堂记录每人进出课堂的时间, 课程结束时导出名单并与学习通对照。

(3) 参加上课但未认真听课。有部分自律能力较差的学生进入课堂后, 把手机或电脑置于一旁 就去干其他事情。曾经有一次笔者在课堂上提问一名学生, 千呼万唤均未响应, 课后询问才告知是 下楼取快递去了。而有部分学生, 课堂测验题的成绩非常低, 间接也体现其并未认真上课。针对这 些敷衍了事的行为, 采取随机点名提问、随时发布问题、增加课堂测验比重的方式, 加强学生的自 我管控能力, 及时了解学生的在线学习状态。这种方式执行后, 效果立竿见影。学生的测验和作业 成绩也有了明显提高。

(4) 学习视频时快进或切换页面。部分学生采用快进的方式观看视频, 完成任务点。甚至有部分 学生将视频播放着但切换到其他页面做其他事情, 极容易错过一些重难点。根据这种情况, 通过设 置防拖拽、防窗口切换、弹题等, 督促学生在学习时集中精力。

(5) 网络平台卡顿或崩溃现象。由于全国范围内线上教学对网络带来的巨大压力, 许多网站出 现了卡顿或崩溃现象。以学习通为例, 在上课高峰期难以登录, 或登录了无法发起签到, 无法学习 章节中的材料。针对这样的问题, 及时改用腾讯课堂及 QQ 群双签的方式。针对无法学习课程材料 问题的解决方案, 则是直接发送相关材料至 $\mathrm{QQ}$ 群内供学生下载学习。然而, 这样的备选方式缺少 了学习通的任务点统计功能。为此, 笔者特别根据学习内容在视频内插入测验题, 或采用在学习完 成后增加测验题的方式, 督促学生一定要认真完成学习任务才能保证答题准确率。

(6) 学生端网络掉线。地方普通高校很多学生来自农村或山区家庭, 家里网络条件较差, 掉线的 现象时有发生。为了保证学生不受网络掉线带来的影响, 比对众多直播软件后, 笔者选择具有回放 功能的腾讯课堂进行课程直播。直播结束后, 在 $24 \mathrm{~h}$ 内将会生成回放的课程视频。教师将回放的课 程视频发送至 QQ 群, 学生可以有选择地观看学习, 弥补网络掉线所落下的课程。同时, 也给好学 的学生提供了再次回顾重难点内容的机会。

(7) 测验或作业题抄袭。在线下课程中, 作业抄袭的现象在所难免, 线上课程的作业抄袭同样不 容乐观。为了减少学生抄袭的机会, 在设置题目时设置成题库形式。采用学习通发放题目, 将其设 置成随机抽题、题目乱序的方式, 并且将 “允许学生粘贴答案的选项” 去掉 ${ }^{[9]}$ 。另一方面, 增加主观 题目, 尤其是材料化学这门课程要求学生对材料的结构、性能和应用等方面有全面的了解, 因此将 所学的新材料以主观题的形式发放给学生进行分析, 学生各抒己意, 答案各不相同但又不偏离题意, 起到了非常好的效果。

\section{3 针对学生特点开展线上教学的经验总结}

通过数周的线上教学工作, 不断磨合改进, 笔者总结出几点针对地方普通高校化学专业学生的 线上教学经验:

(1) 对不同学生摸底。向辅导员、班主任、班委等多方面了解班上每位学生的家庭、学习情况, 对好学但家庭困难的学生给予针对性辅导, 对于迟到、旷课或作业完成情况不好的学生, 及时了解 
原因, 跟进其学习。

(2) 直播授课、视频学习、互动讨论的时长应安排合理。一般情况下, $90 \mathrm{~min}$ 的课程, 60-70 min 钟时间直播授课讲重点, 10-20 min 学生学习视频材料的前沿知识, 最后留下约 $10 \mathrm{~min}$ 的互动讨论 及测验时间。直播讲授和视频学习应穿插进行, 避免由于网络授课使学生产生视觉和听觉疲劳, 导 致精神难以集中, 影响学习效果。

(3) 课堂上签到、互动、提问、测验等环节必不可少。由于线上教学无法面对面, 这些手段可让 教师实时掌握学生是否在线学习、学习状态如何, 尤其是对部分自律性比较差的学生, 督促作用非 常显著。

(4) 课堂测验题型和数量随机应变, 课后作业题量应适中。为了及时检验学生的随堂学习效果, 课堂测验的题型和数量应根据需要及时调整。比如, 下午的课程学生容易犯困, 可适当地增加主观 题、在视频中插入题目、在每一环节结束后发放一两道测验题等。而课后作业题是学生在课余时间 完成的, 据笔者了解, 如今大部分课程采用线上教学后, 都设置有课后作业题。因此, 需要根据课 程的重难点设置合适数量的作业题, 不宜过多, 否则学生难以高质量完成。

\section{4 结语}

当前, 网络上流行着一句话: 疫情过后, 学生将会出现两极分化, 原因就是两个字一一自律。在 这种情况下, 让自律的学生更自律, 不自律的学生变得自律或 “被迫” 自律, 教师在其中的作用无 疑是至关重要的。除了扮演知识传授者的角色外, 教师同时也要承担起课堂管理和学生引导的责任。 针对地方普通高校学生的特点, 笔者根据材料化学课程授课过程的经历, 分析了线上教学实施过程 中遇到的问题和解决方案, 并总结了开展线上教学的经验。随着疫情的发展, 线上教学后续还存在 很多的不确定性。希望本文能为地方普通高校化学专业线上教学提供有益的参考。

\section{参 考 文 献}

[1] 教育部应对新型冠状病毒感染肺炎疫情工作领导小组办公室关于在疫情防控期间做好普通高等学校在线教学组织与管理工作的指导意 见. [2020-02-04]. http://www.moe.gov.cn/srcsite/A08/s7056/202002/t20200205_418138.html.

[2] 刘贤响. 大学化学, 2020, 35 (5), 10.

[3] 腾讯课堂极速版操作指南. [2020-03-07]. https://ke.qq.com/course/577567.

[4] 材料科学基础(中南大学), 中国大学 MOOC. [2020-03-07]. https://www.icourse163.org/course/CSU-1003509003.

[5] 什么是位错. [2020-03-07]. https://www.bilibili.com/video/av69905689?from=search\&seid=1790791457026178274.

[6] 什么是螺位错. [2020-03-07]. https://www.bilibili.com/video/av79405784/?spm_id_from=333.788.videocard.2.

[7] 超神奇！形状记忆物质. [2020-03-07]. https://www.bilibili.com/video/av8524321/?spm_id_from=333.788.videocard.4.

[8]＼cjkstart神奇的记忆合金！让假花在光照下尽情绽放. [2020-03-07]. https://www.ixigua.com/i6625827280994173444/?logTag=aaZr02gyFaybJR754W1Gy.

[9] 一平三端使用教程. [2020-02-19]. https://special.zhexuezj.cn/mobile/mooc/tocourse/200399651?appId=1000. 